\title{
Local influence of high molecular polyethylene particles on heterotopic ossification
}

\author{
LIN-RU ZENG ${ }^{1}$, FANG-BING ZHU ${ }^{1}$, JIAN-YUE WANG ${ }^{1}$, QIAO HOU ${ }^{1}$, ZHEN-SHUANG YUE $^{1}$, \\ SHI-GUI YAN $^{2}$, REN-FU QUAN ${ }^{1}$ and YING-LIANG ZHANG ${ }^{1}$ \\ ${ }^{1}$ Department of Orthopaedic Surgery, Xiaoshan Traditional Chinese Medical Hospital, Hangzhou, Zhejiang 311200; \\ ${ }^{2}$ Department of Orthopaedic Surgery, The Second Affiliated Hospital, School of Medicine, Zhejiang University, \\ Hangzhou, Zhejiang 310009, P.R. China
}

Received September 7, 2016; Accepted March 6, 2017

DOI: $10.3892 /$ etm.2017.4327

\begin{abstract}
We studied the effect of molecular polyethylene particles on local heterotopic ossification. A total of 36 healthy Sprague-Dawley rats were randomly divided into the control group $(n=18)$ and the observation group $(n=18)$. High molecular polyethylene particles were injected to rupture Achilles tendon position in the observation group, and normal saline was injected in the control group. X-ray examinations were conducted on Achilles tendon in the 4th, 8th and 12th week after operation. The incidence rate of heterotopic ossification was evaluated, and bone trabecula morphological structure was studied under optical microscope after hematoxylin and eosin staining. Bone morphogenetic protein 2 (BMP-2), transforming growth factor- $\beta$ (TGF- $\beta$ ), interleukin-1 (IL-1), tumor necrosis factor- $\alpha$ (TNF- $\alpha)$, runt-related transcription factor 2 (Runx2) and matrix metalloproteinase-9 (MMP-9) expression levels were also measured. Our results showed that heterotopic ossification incidence in the observation group was significantly lower than that in the control group. Achilles tendon structure in the control group increased in volume, and its texture was harder and cartilage-like. In the observation group, trabecular bone volume, thickness and quantity were more than those observed in the control group. BMP-2, TGF- $\beta$, IL-1, TNF- $\alpha$, Runx 2 and MMP-9 levels in the observation group were significantly lower than those in the control group. We concluded that, high molecular polyethylene particles had a significant inhibiting effect on local heterotopic ossification.
\end{abstract}

Correspondence to: Dr Ying-Liang Zhang, Department of Orthopaedic Surgery, Xiaoshan Traditional Chinese Medical Hospital, 152 Yucai Road, Hangzhou, Zhejiang 311200, P.R. China

E-mail: zw5k37@163.com

Key words: high molecular polyethylene particles, bone trabecula, heterotopic ossification, bone morphogenetic protein 2, transforming growth factor- $\beta$, interleukin- 1 , tumor necrosis factor- $\alpha$, runt-related transcription factor 2, matrix metalloproteinase-9

\section{Introduction}

Heterotopic ossification is the abnormal growth of bone in the non-skeletal tissues including muscle, tendons, or other soft tissue. Heterotopic ossification may occur in skeletal muscle wound, bone joint operation and the nervous system impairment (1). With the increase in the number of artificial joint replacement surgeries, the incidence rate of heterotopic ossification is increasing every year (2). Serious heterotopic ossification may result in arthrocele, pain, joint movement disorder and even loss of mobility. It may also cause neurological problems and pressure ulcers and seriously reduce patients' life quality (3). The specific mechanism of heterotopic ossification is unclear, however there are several theories including (4): i) Trauma or orthopedic operation results in local bone tissue destruction, muscular death and haematoma formation; ii) paracrine and inflammation in injured tissues can release various cell factors, which allows local cell signal to change; iii) mesenchymal stem cells migrate toward injured position, and differentiate into cartilage cells and osteocyte; and iv) surrounding tissues provide a proper and stable internal environment for continuous growth of heterotopic bone tissue.

Wear particles may be related to osteolysis around prosthesis, which resulted in aseptic loosening of artificial joint and implantation failure (5). Wear particles may stimulate macrophages to produce interleukin-1 (IL-1), IL-6 and tumor necrosis factor- $\alpha$ (TNF- $\alpha)$, which play an important role in osteoclast occurrence, differentiation and maturity (6). Wear particles may also stimulate osteoblast around prosthesis to secrete core binding factor receptor activator of nuclear factor- $\kappa \mathrm{B}$ ligand (RANKL) to reduce osteoprotegerin (7). Blocking wear particles stimulus response link and reducing ability of osteoclast production and activation had potential benefits to relieve or prevent bone around prosthesis dissolving.

After in-depth analysis on possible mechanism involved in aseptic loosening of artificial joint, we planned to introduce wear particles into the treatment process. We discussed the feasibility and possible mechanism by establishing animal model formed by high molecular polyethylene particles local intervention and inhibition on heterotopic ossification, which provided a new method to prevent heterotopic ossification. 

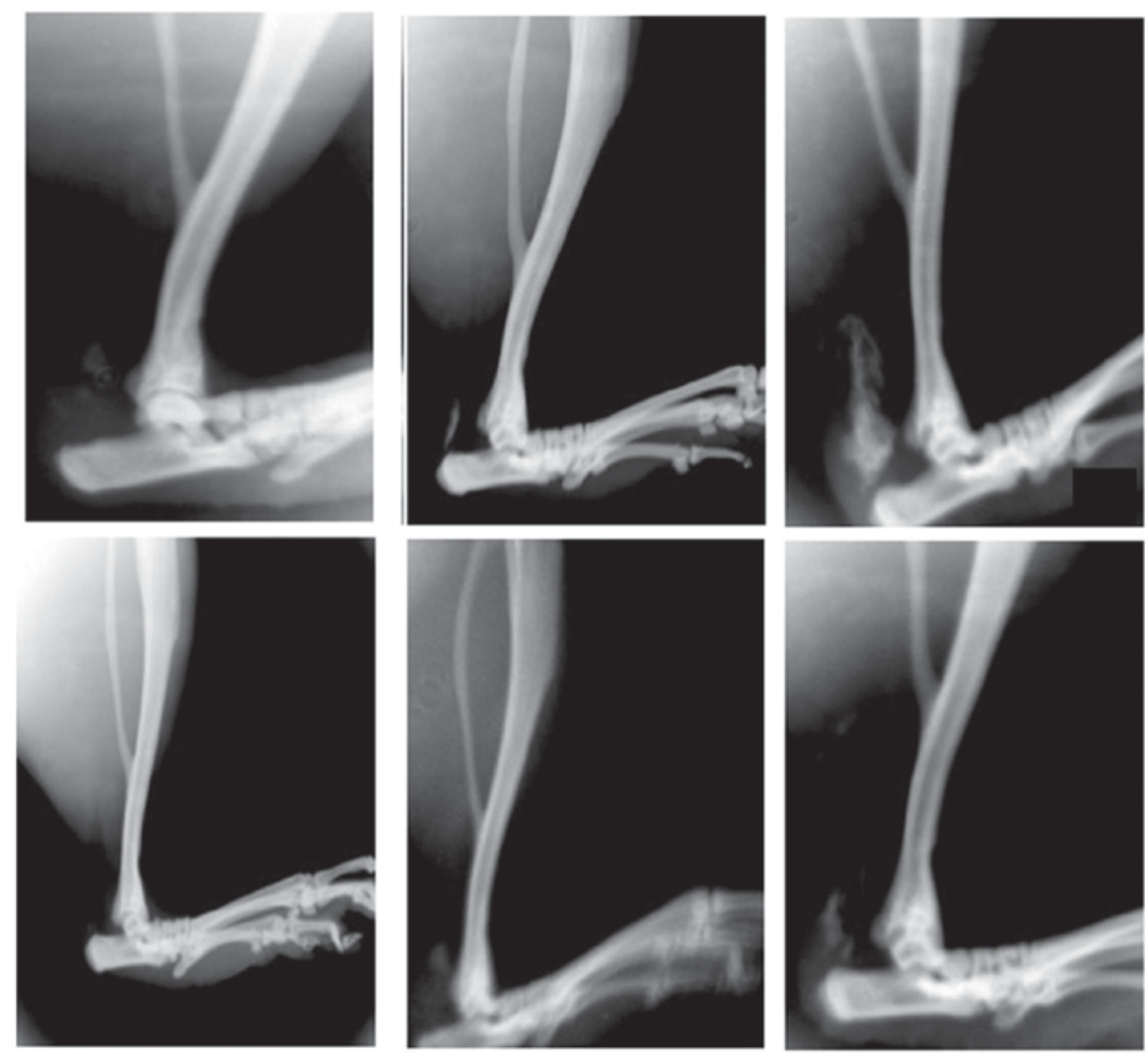

Figure 1. Incidence rate of heterotopic ossification by X-ray (upper ones are control group, the lower ones are observation group. From left to right: 4,8 and 12 weeks).

\section{Materials and methods}

Experimental animals. A total of 36 healthy Sprague-Dawley rats aged from 6 to 8 weeks with average weight of $180 \mathrm{~g}$ were used in this study. They were obtained from Shanghai Sangon Animal Experimental Center (Shanghai, China), and were fed normally for one week prior to the beginning of the experiment. Pentobarbital $(30 \mathrm{mg} / \mathrm{g})$ was injected into abdominal cavity for anesthesia, and posterolateral approach of right leg was used to transect at midpoint of Achilles tendon, clamp was used to clip at both ends of fractured Achilles tendon and no suture was used for Achilles tendon. X-ray and bone histomorphometry were used for to determine success of the operation.

Research method. Rats were randomly divided into the control group $(\mathrm{n}=18)$ and the observation group $(\mathrm{n}=18)$, and high molecular polyethylene particles $(1.0 \mathrm{wt} \%)$ were injected to rupture Achilles tendon position in the observation group, and normal saline was injected in the control group. Skin was sutured, and rats were fed routinely and observed. Antibiotic was used to prevent infection. X-ray examinations were conducted on Achilles tendon in the 4th, 8th and 12th week after operation. The incidence rate of heterotopic ossification was evaluated, and bone trabecula morphological structure was studied under optical microscope (BX-42; Olympus, Tokyo, Japan) after hematoxylin and eosin (H\&E) staining. Bone morphogenetic protein 2 (BMP-2), transforming growth factor- $\beta$ (TGF- $\beta$ ), IL-1, TNF- $\alpha$, runt-related transcription factor 2 (Runx2) and matrix metalloproteinase-9 (MMP-9) expression levels were also measured.
Preparation of high molecular polyethylene particles. The mean diameter of high molecular polyethylene particles was $3.6 \mu \mathrm{m}$ (range, $0.8-23 \mu \mathrm{m}$ ), with irregular shape. Particles were dissolved in 75\% ethyl alcohol, shaken and washed 4 times (one hour each time) at room temperature. Consequently, particles were soaked in $100 \%$ ethyl alcohol to eliminate endotoxin.

$X$-ray examination. To study the formation of heterotopic bone, injured Achilles's tendons were examined with a Kodak X-ray machine (AA400; Kodak, Rochester, NY, USA).

Visual observation and histological examination of Achilles tendon. Rats were sacrificed by quick neck removal method and samples from Achilles tendons were collected. The color, thickness, elasticity and flintiness of tendon was examined and heterotopic bone formation was verified. Samples were fixed with $10 \%$ neutral formalin for $24 \mathrm{~h}$ and decalcified for 1 week with $15 \%$ EDTA. Samples were then dehydrated using gradient ethanol and then embedded with transparent paraffin in order to prepare 5- $\mu \mathrm{m}$ sections. H\&E straining was performed and bone trabecula structure was observed under Olympus optical microscope (BX-42; Olympus). This study was approved by the Animal Ethics Committee of Zhejiang University Animal Center.

Immunohistochemical staining. Frozen sections were fixed in cold acetone for $15 \mathrm{~min}$, and hatched in $3 \%$ hydrogen peroxide for $10 \mathrm{~min}$ at room temperature to eliminate endogenous peroxidase. Samples were washed 3 times (5 min each time) 
Table I. Histological examination comparison.

\begin{tabular}{ccccc}
\hline Category & $\begin{array}{c}\text { Control } \\
\text { group }\end{array}$ & $\begin{array}{c}\text { Observation } \\
\text { group }\end{array}$ & t-test & P-value \\
\hline $\begin{array}{c}\text { Trabecular } \\
\text { bone volume }\end{array}$ & & & & \\
4th week & $2.2 \pm 0.5$ & $3.6 \pm 0.8$ & 5.632 & 0.024 \\
8th week & $2.3 \pm 0.6$ & $4.5 \pm 1.1$ & 6.432 & 0.016 \\
12th week & $2.4 \pm 0.6$ & $5.3 \pm 1.5$ & 7.412 & 0.009 \\
Thickness & & & & \\
4th week & $1.5 \pm 0.4$ & $1.9 \pm 0.6$ & 4.236 & 0.032 \\
8th week & $1.6 \pm 0.5$ & $2.2 \pm 0.8$ & 4.958 & 0.025 \\
12th week & $1.7 \pm 0.6$ & $2.6 \pm 1.2$ & 5.237 & 0.021 \\
Quantity & & & & \\
4th week & $2.4 \pm 0.9$ & $3.0 \pm 0.9$ & 4.526 & 0.030 \\
8th week & $2.3 \pm 0.8$ & $3.5 \pm 1.3$ & 5.714 & 0.022 \\
12th week & $2.4 \pm 1.0$ & $3.9 \pm 1.5$ & 6.326 & 0.017 \\
\hline
\end{tabular}

with phosphate-buffered saline (PBS) and primary antibody was then added. Primary antibodies including rabbit monoclonal BMP-2 antibody (dilution, 1:50; cat. no. SAB1306267), rabbit monoclonal TGF- $\beta$ antibody (dilution, 1:50; cat. no. SAB4301267) rabbit polyclonal IL-1 antibody (dilution, 1:50; cat.no. SAB4503272) rabbit monoclonal TNF- $\alpha$ antibody (dilution, 1:50; cat. no.SAB2108244), rabbit monoclonal Runx2 antibody (dilution, 1:50; cat. no. SAB4301114) and rabbit polyclonal MMP-9 antibody (dilution, 1:50; cat. no. HPA001238) were from Sigma-Aldrich (St. Louis, MO, USA). For negative control we used PBS instead of primary antibody. Samples were soaked in $37^{\circ} \mathrm{C}$ electrothermal constant-temperature water tank and were washed with PBS three times (5 min each time). Secondary goat anti-rabbit (HRP) IgG antibody (dilution, 1:2,000; cat. no. ab6721) from Abcam (Cambridge, MA, USA) was then added and samples were incubated for $30 \mathrm{~min}$ at room temperature. Samples were the verified under optical microscope, followed by flushing, re-staining, dehydration and mounting. When faint yellow color was observed in the cytoplasm or endochylema, sample was marked as positive. We selected 5 high-power field (x400) randomly, and made the overall rating by straining intensity combined with positive cell percentage.

Statistical analysis. SPSS 20.0 statistical software (IBM, Armonk, NY, USA) was used for statistical analysis. Gaussian distribution data are presented as mean \pm standard deviation. For comparison t-test or variance analysis by repeatedly measuring data were used. Qualitative data are presented as rate, and for comparison $\chi^{2}$ test was used. $\mathrm{P}<0.05$ was considered to indicate a statistically significant difference.

\section{Results}

Heterotopic ossification incidence comparison. Four weeks after operation, there were 8 rats with heterotopic ossification in the control group and 2 in the observation group. Eight weeks after operation, there were 14 rats with heterotopic ossification
Table II. Inflammatory factor expression quantity comparison.

\begin{tabular}{|c|c|c|c|c|}
\hline Category & $\begin{array}{l}\text { Control } \\
\text { group }\end{array}$ & $\begin{array}{l}\text { Observation } \\
\text { group }\end{array}$ & t-test & P-valu \\
\hline \multicolumn{5}{|l|}{ BMP-2 } \\
\hline 4th week & $5.6 \pm 1.2$ & $2.3 \pm 0.6$ & 5.236 & 0.032 \\
\hline 8th week & $9.4 \pm 1.8$ & $5.4 \pm 0.9$ & 6.421 & 0.025 \\
\hline 12th week & $11.5 \pm 2.2$ & $7.6 \pm 1.2$ & 7.523 & 0.014 \\
\hline \multicolumn{5}{|l|}{ TGF- $\beta$} \\
\hline 4th week & $3.6 \pm 0.8$ & $1.2 \pm 0.4$ & 5.629 & 0.029 \\
\hline 8th week & $7.2 \pm 1.3$ & $2.3 \pm 0.9$ & 6.532 & 0.023 \\
\hline 12 th week & $9.5 \pm 1.9$ & $4.6 \pm 1.3$ & 7.524 & 0.015 \\
\hline \multicolumn{5}{|l|}{ IL-1 } \\
\hline 4th week & $4.5 \pm 1.1$ & $2.1 \pm 0.7$ & 5.236 & 0.033 \\
\hline 8th week & $6.8 \pm 1.9$ & $3.3 \pm 1.1$ & 5.895 & 0.026 \\
\hline 12 th week & $8.4 \pm 2.2$ & $5.2 \pm 1.6$ & 6.632 & 0.023 \\
\hline \multicolumn{5}{|l|}{ TNF- $\alpha$} \\
\hline 4th week & $5.6 \pm 1.3$ & $2.4 \pm 0.6$ & 5.426 & 0.030 \\
\hline 8th week & $9.4 \pm 1.8$ & $4.3 \pm 1.2$ & 6.329 & 0.026 \\
\hline 12th week & $11.7 \pm 2.4$ & $6.6 \pm 1.7$ & 7.521 & 0.015 \\
\hline \multicolumn{5}{|l|}{ Runx2 } \\
\hline 4th week & $3.3 \pm 0.6$ & $1.2 \pm 0.3$ & 4.629 & 0.038 \\
\hline 8th week & $7.2 \pm 1.4$ & $2.3 \pm 0.8$ & 5.638 & 0.030 \\
\hline 12th week & $9.5 \pm 2.3$ & $3.4 \pm 1.5$ & 6.429 & 0.024 \\
\hline \multicolumn{5}{|l|}{ MMP-9 } \\
\hline 4th week & $6.2 \pm 1.3$ & $3.2 \pm 1.1$ & 5.826 & 0.032 \\
\hline 8th week & $9.5 \pm 2.4$ & $4.5 \pm 1.8$ & 6.754 & 0.025 \\
\hline 12th week & $11.9 \pm 3.2$ & $6.7 \pm 2.4$ & 7.895 & 0.013 \\
\hline
\end{tabular}

BMP-2, bone morphogenetic protein 2; TGF- $\beta$, transforming growth factor- $\beta$; IL-1, interleukin-1; TNF- $\alpha$, tumor necrosis factor- $\alpha$; Runx2, runt-related transcription factor 2; MMP-9, matrix metalloproteinase-9.

in the control group and 5 in the observation group. Twelve weeks after operation, there were 18 rats with heterotopic ossification in the control group and 9 in the observation group. Heterotopic ossification incidence in the observation group was significantly lower than that in the control group and the difference had statistical significance $(\mathrm{P}<0.05)$. The incidence increased in both groups with time (Fig. 1).

Visual inspection and histological examination. Achilles tendon structure in the control group increased in volume, and its texture was harder and cartilage-like. With H\&E staining, cartilage cells and granulation tissue proliferation were observed. In the observation group, trabecular bone volume, thickness and quantity were more than those observed in the control group and the difference had statistical significance $(\mathrm{P}<0.05)$ (Table I).

Inflammatory factors. BMP-2, TGF- $\beta$, IL-1, TNF- $\alpha$, Runx 2 and MMP-9 levels in observation group were significantly lower than those in the control group, and the difference had statistical significance $(\mathrm{P}<0.05)$ (Table II). 


\section{Discussion}

Heterotopic ossification has similar histological and imaging features as normal bone (8). Backbone is smooth, irregular in shape, benign tumor-like mature bone, extending to normal bone surface and not invading bone cortex. Bone metabolic activity of heterotopic ossification is high. Bone mineralization rate, suture width and osteoblast and osteoclast number increase significantly, and it has stronger rate of mineralization during the early stage of proliferation and differentiation (9).

Treatment of heterotopic ossification is based on severity, range and joint function disturbance (10). It includes medication, radiation and surgical intervention (11). Non-steroidal anti-inflammatory medications and diphosphates are the main drugs used in the treatment of the heterotopic ossification (12). There are a few disadvantages associated with these drugs. These include serious side effects and hemorrhage in digestive tract (13). Ossification may continue once medications are interrupted (14). Beside its carcinogenic risk, radiotherapy cannot reduce the mature heterotopic bone volume (15).

We built a rabbit-human artificial joint aseptic loosening model successfully, and discovered that alendronate sodium bone cement local load system effectively prevented periprosthetic osteolysis and bone absorption mediated by titanium particles. It also improved periprosthetic bone mineral density, increase prosthesis, bone interface shear strength and periprosthetic bone mass fraction (16). We locally applied high molecular polyethylene particles in heterotopic ossification model, and discovered that heterotopic ossification incidence in the observation group was significantly lower than that in the control group.

BMP-2, TGF- $\beta$, IL-1, TNF- $\alpha$, Runx 2 and MMP-9 levels in observation group were significantly lower than those in the control group. BMP-2 is an osteogenic induction factor, which can facilitate osteoblastic differentiation and regulate the occurrence of heterotopic ossification. BMP-2 expression level was shown to be related to bone formation level (17). TGF- $\beta$ regulates cells proliferation and differentiation, increases the synthesis of extracellular matrix and facilitates cartilage tissue collagen synthesis (18). BMP-2 affects the occurrence of entochondrostosis under the regulation of TGF- $\beta$. Inflammatory cytokines such as IL-1 and TNF- $\alpha$, produced by post-trauma tissue, can stimulate the expression of BMP-2, increase proliferation and differentiation of mesenchymal stem cells in muscular tissue and increase bone formation (19). Runx2 is an osteoblast specific transcription factor, which directly regulates type I collagen and osteocalcin bone gene expression and participates in ECM signal path activation process of osteogenic precursor cells (20). MMP-9 is a saccharifying protease, which is secreted by interstitial cells, and participates in nuclear migration of endothelial cells, epithelial cells, fibroblast and keratinocytes. It is an important indicator for early extracellular matrix recombination (21). MMP-9 regulates and degrades various types of extracellular matrix, and can activate other types of MMP protein and trigger an inflammatory cascade. MMP-9 participates in bone remodeling and angiogenesis process, which can be regarded as biomarker with higher sensitivity and specificity in neurological heterotopic ossification (22).
We concluded that, high molecular polyethylene particles had a significant inhibiting effect on local heterotopic ossification. This may be related to the release of local inflammatory factors.

\section{Acknowledgements}

This study was funded by the Xiaoshan Science and Technology Bureau Funds (grant no. 2013325)

\section{References}

1. Zhao X, Cai XZ, Shi ZL, Zhu FB, Zhao GS and Yan SG: Low-intensity pulsed ultrasound (LIPUS) may prevent polyethylene induced periprosthetic osteolysis in vivo. Ultrasound Med Biol 38: 238-246, 2012.

2. Müseler AC, Grasmücke D, Jansen O, Aach M, Meindl R, Schildhauer TA and Citak M: In-hospital outcomes following single-dose radiation therapy in the treatment of heterotopic ossification of the hip following spinal cord injury-an analysis of 444 cases. Spinal Cord 19: 145-146, 2016.

3. Bowman SH, Barfield WR, Slone HS, Shealy GJ and Walton ZJ: The clinical implications of heterotopic ossification in patients treated with radial head replacement for trauma: a case series and review of the literature. J Orthop 13: 272-277, 2016.

4. Suzuki H, Ito Y, Shinohara M, Yamashita S, Ichinose S, Kishida A, Oyaizu T, Kayama T, Nakamichi R, Koda N, et al: Gene targeting of the transcription factor Mohawk in rats causes heterotopic ossification of Achilles tendon via failed tenogenesis. Proc Natl Acad Sci USA 113: 7840-7845, 2016.

5. Yuan P, Wang WC, Li ZH and Mao XZ: Could insertion of the particles that induce osteolysis be a new treatment option in heterotopic ossification? Med Hypotheses 73: 27-28, 2009.

6. Eid K, Zelicof S, Perona BP, Sledge CB and Glowacki J: Tissue reactions to particles of bone-substitute materials in intraosseous and heterotopic sites in rats: discrimination of osteoinduction, osteocompatibility, and inflammation. J Orthop Res 19: 962-969, 2001.

7. Lee K, Kim H, Park HS, Kim KJ, Song H, Shin HI, Kim HS, Seo D, Kook H, Ko JH, et al: Targeting of the osteoclastogenic RANKL-RANK axis prevents osteoporotic bone loss and soft tissue calcification in coxsackievirus B3-infected mice. J Immunol 190: 1623-1630, 2013.

8. Pavey GJ, Qureshi AT, Tomasino AM, Honnold CL, Bishop DK, Agarwal S, Loder S,Levi B, Pacifici M, Iwamoto M, et al: Targeted stimulation of retinoic acid receptor- $\gamma$ mitigates the formation of heterotopic ossification in an established blast-related traumatic injury model. Bone 90: 159-167, 2016.

9. Rosteius T, Suero EM, Grasmücke D, Aach M, Gisevius A, Ohlmeier M, Meindl R, Schildhauer TA and Citak M: The sensitivity of ultrasound screening examination in detecting heterotopic ossification following spinal cord injury. Spinal Cord 28: 123-124, 2016

10. Schneider JC, Simko LC, Goldstein R, Shie VL, Chernack B, Levi B, Jayakumar P, Kowalske KJ, Herndon DN, Gibran NS, et al: Predicting heterotopic ossification early after burn injuries: a risk scoring system. Ann Surg 24: 17-18, 2016.

11. Selbong U, Rashidi R and Sidebottom A: Management of recurrent heterotopic ossification around total alloplastic temporomandibular joint replacement. Int J Oral Maxillofac Surg 45: 1234-1236, 2016.

12. Rath E, Warschawski Y, Maman E, Dolkart O, Sharfman ZT, Salai M and Amar E: Selective COX-2 inhibitors significantly reduce the occurrence of heterotopic ossification after hip arthroscopic surgery. Am J Sports Med 44: 677-681, 2016.

13. Løken S: Hip arthroscopy and heterotopic ossification: is NSAID prophylaxis justified? Commentary on an article by James T. Beckmann, MD, MS, et al.: 'Effect of naproxen prophylaxis on heterotopic ossification following hip arthroscopy: a double-blind randomized placebo-controlled trial'. J Bone Joint Surg Am 97: e80, 2015.

14. Yeung M, Jamshidi S, Horner N, Simunovic N, Karlsson J and Ayeni OR: Efficacy of nonsteroidal anti-inflammatory drug prophylaxis for heterotrophic ossification in hip arthroscopy: a systematic review. Arthroscopy 32: 519-525, 2016. 
15. Pakos EE, Tsekeris PG, Paschos NK, Pitouli EJ, Motsis EK and Xenakis TA: The role of radiation dose in a combined therapeutic protocol for the prevention of heterotopic ossification after total hip replacement. J BUON 15: 74-78, 2010.

16. Zhu FB, Cai XZ, Yan SG, Zhu HX and Li R: The effects of local and systemic alendronate delivery on wear debris-induced osteolysis in vivo. J Orthop Res 28: 893-899, 2010.

17. Mao L, Yano M, Kawao N, Tamura Y, Okada K and Kaji H: Role of matrix metalloproteinase-10 in the BMP-2 inducing osteoblastic differentiation. Endocr J 60: 1309-1319, 2013.

18. Suutre S, Toom A, Arend A and Selstam G: Bone tissue content of TGF-beta2 changes with time in human heterotopic ossification after total hip arthroplasty. Growth Factors 27: 114-120, 2009.

19. Lencel P, Delplace S, Pilet P, Leterme D, Miellot F, Sourice S, Caudrillier A, Hardouin P, Guicheux J and Magne D: Cell-specific effects of TNF- $\alpha$ and IL-1 $\beta$ on alkaline phosphatase: implication for syndesmophyte formation and vascular calcification. Lab Invest 91: 1434-1442, 2011.
20. Shrivats AR, McDermott MC, Klimak M, Averick SE, Pan H, Matyjaszewski K,Mishina Y and Hollinger JO: Nanogel-mediated RNAi against Runx2 and Osx inhibits osteogenic differentiation in constitutively active BMPR1A osteoblasts. ACS Biomater Sci Eng 1: 1139-1150, 2015.

21. Shi W, Xiao H, Xue F and Wu J: Dynamic changes of matrix metalloproteinase 9 in heterotopic ossification of rat model. Zhongguo Xiu Fu Chong Jian Wai Ke Za Zhi 28: 1133-1138, 2014 (In Chinese).

22. Rodenberg E, Azhdarinia A, Lazard ZW, Hall M, Kwon SK, Wilganowski N, Salisbury EA, Merched-Sauvage M, Olmsted-Davis EA, Sevick-Muraca EM, et al: Matrix metalloproteinase-9 is a diagnostic marker of heterotopic ossification in a murine model. Tissue Eng Part A 17: 2487-2496, 2011. 